\title{
Perancangan Kampanye Sosial Mengatasi Penyakit Maag
}

\author{
Nurul Afifah Novianti ${ }^{1}$, Irwan Tarmawan ${ }^{2}$ \\ ${ }^{1,2}$ Desain Komunikasi Visual, Fakultas Desain, Universitas Komputer Indonesia, Bandung \\ Email: ${ }^{1}$ nurulafifah@mahasiswa.unikom.ac.id, ${ }^{2}$ irwan.tarmawan@email.unikom.ac.id
}

\begin{abstract}
Abstrak: Maag merupakan penyakit yang menyerang asam lambung yang di karenakan luka atau peradangan lambung yang muncul berupa nyeri bagian ulu hati, mual, rasa cepat kenyang. Penyebabnya yaitu pola makan tidak sehat dan pola hidup yang tidak teratur. Banyaknya masyarakat yang menyepelekan penyakit ini, sehingga menjadi hal yang lumrah walaupun sebenarnya tidak bisa disepelekan. Namun banyak masyarakat belum banyak mengetahui bahwa stress merupakan penyebab asam lambung naik bahkan keluhan pada maag yang disebabkan faktor kecemasan atau stress. Fenomenanya masih banyak masyarakat yang menganggap remeh terkait penyakit maag. Hal tersebut di karenakan kebiasaan pola hidup tidak sehat dan generasi aktif lebih rentan terkena penyakit maag. Kesimpulan diatas akan dilakukan perancangan kampanye sosial dalam perancangan ini bertujuan untuk meminimalisir penyakit maag terutama yang berdampak dari stress.
\end{abstract}

Kata kunci: kampanye sosial, maag, stress, ulu hati

Abstract: Ulcer is a disease that attacks stomach acid. This disease is caused by sores or inflammation in the stomach that appears in the form of pain in the pit of the stomach, nausea, feeling full quickly in the stomach. The reason is because of uplexus. hy eating schedules and irregular lifestyle. Many people underestimate this disease. So it becomes a common thing even though it really can't be underestimated. But many people who do not know that stress is the cause of stomach acid rising into the throat. Even complaints of this disease caused by anxiety or stress factors that reach 70-80\%. There are still many people who underestimate this ulcer disease. This is because the habits of unhealthy lifestyles and active generations are more susceptible to heartburn. From the conclusions above will be carried out the design of social campaigns, in this design aims to minimize ulcer disease, especially those that impact from stress.

Keywords: social campaign, heartburn, stress, solar plexus. 


\section{PENDAHULUAN}

Di Indonesia kesehatan masyarakat masih belum banyak di tanggani mulai dari masalah penyakit menular sampai penyakit tidak menular. Kasus pada penyakit tidak menular (PTM) banyaknya disebabkan oleh gaya hidup tidak sehat karena modernisasi Kemenkes, 2013 dalam Merita (2016, h. 51). Salah satu penyakit tidak menular yaitu gastritis atau biasa disebut maag. Menurut Sukarmin (2012, h. 147), Maag atau gastritis adalah perandangan pada lambung yang mengakibatkan pembengkakan selaput lendir (mukosa) sehingga terlepasnya lapisan terluar (epitel mukosa superfisial) dapat berakibat gangguan pada saluran pencernaan.

Menurut Abdullah (2008) dalam Jannah M (2011, h. 5), penderita mengalami rasa sakit pada bagian perut kiri bagian atas (ulu hati). Gejala pada penyakit maag yaitu merasa mual, kembung, cepat merasa kenyang dan sering sendawa. Beberapa orang, akan merasa sakit di bagian perut hingga tertusuk sampai belakang. Menurut Sukarmin (2012, h. 147) salah satu penyebab penyakit maag yaitu stres. Menurut penelitian Maniagasi, Elsye Nelci (2019, h. 3), maag bisa disebabkan akibat gangguan fungsional dari lambung. Gangguan fungsional yaitu gangguan pada lambung yang disebabkan dari faktor psikologis. Fenomenanya masih banyak masyarakat lebih mengetahui maag yang diakibatkan pada pola makan yang salah. Keluhan pada maag yang disebabkan faktor kecemasan atau stres yaitu mencapai $70-80 \%$.

Kurangnya tingkat kesadaran masyarakat memperhatikan kesehatan dan mengatur tingkat stres bisa terjadi karena faktor lingkungan. stres yang berlebihan membuat produksi asam lambung yang berlebih bisa menyebabkan ketidaknyamanan lambung. Stres yaitu respon fisiologis tubuh terhadap situasi fisik dan emosional. Stres atau cemas berkepanjangan dapat meningkatkan asam lambung karena dalam keadaaan stres seperti beban kerja, tugas yang menumpuk, takut dan terburu-buru. Saat stres, tubuh akan memproduksi hormonekortisol yang membuat tubuh kehabisan mineral dan vitamin B. Dalam penelitian Karwati (2012) dalam Maniagasi, Elsye Nelci (2019, h. 3), penderita maag dengan tingkat stress berlebih mempunyai resiko 3,370 kali lebih tinggi dibanding dengan maag yang tidak stres.

Dilansir pada artikel kalbe.co.id (2020) genarasi yang rentan terkena penyakit maag yaitu genarasi muda yang produktif. Alasannya karena gaya hidup yang kurang tepat dan mengkonsumsi makanan yang bisa merangsang asam lambung. Menurut WHO (2011) dalam situsnya who.int diakses pada 17 Juli 2020, Kejadian penyakit ini sebanyak 1,8-2,1 juta orang di seluruh dunia. Hasil penelitian yang dilakukan pada Kementrian Kesehatan, kejadian di Indonesia bisa di bilang cukup tinggi mencapai $91,6 \%$ di susul oleh Jakarta sebesar 50\%, Denpasar 46\%, Bandung $35,5 \%$, Palembang 32, Aceh 31,7\%, Surabaya 31,2\%, dan Pontianak 31,2\%.

Bedasarkan data hasil penjabaran diatas, masih banyak masyarakat yang menganggap remeh terkait penyakit maag. Hal tersebut di karenakan kebiasaan gaya hidup tidak sehat dan kebiasaan pola makan tidak sehat yang memicu stres sehingga timbulnya reaksi pada asam lambung yang mengakibatkan bertambahnya jumlah asam lambung. Jika dibiarkan dan terjadi terus menerus, maka dampak 
penyakit ini bisa menyebabkan komplikasi ke organ lain, menggangu pernafasan bahkan kematian. Berdasarkan observasi iklan pada penyakit maag, masih banyak yang menghubungkan pada pola makan sehingga kalbe ingin membuat program kampanye penyakit maag yang diakibatkan dari stres.

PT.Kalbe adalah perusahaan farmasi yang berkembang pesat. Awalnya dimulai dari usaha sederhana disebuah garasi pada tahun 1966 dan kini menjadi perusahaan farmasi terbesar di Indonesia. Dalam mendirikan perusahaan, wajib melaksanakan tanggung jawab sosial atau Corporate Social Responsibility (CSR) sudah diatur dalam UU PT No.40 Tahun 2007 pada pasal 1 ayat 1 tentang Perseroan Terbatas (PT) bahwa komitmen perusahaan berperan serta dalam ekonomi berkelanjutan untuk meningkatkan kualitas kehidupan yang bermanfaat baik bagi perusahaan, pemerintah, komunitas maupun masyarakat.

Berdasarkan strategi media yang telah digunakan dalam kampanye tersebut, maka perancangan ini akan membuat kampanye berupa film iklan layanan masyarakat untuk perluasan kampanye melalui media online. Menurut Tarmawan (2010, h. 1) iklan merupakan suatu proses komunikasi yang ditujukan untuk mempengaruhi pengetahuan, kepercayaan dan pemikiran masyarakat terkait dengan sesuatu untuk mempengaruhi masyarakat dalm berperilaku. Selain film iklan, perancang akan menginformasikan melalui poster dengan fotografi dan strategi kampanye AISAS.

\section{METODE}

Metode penelitian yang digunakan adalah metode penelitian kualitatif disertai dengan metode deskriptif. Dengan menggunakan metode kualitatif dapat mengetahui sudut pandang para ahli dan masyarakat apa yang dialami oleh masyarakat tentang penyakit maag.

\section{Prosedur Pengambilan Data}

Langkah dalam proses pencarian data menggunakan wawancara, kuisioner, dan website resmi. yang pertama wawancara dengan ahli dibidang spesialis penyakit dalam dan psikolog. Wawancara dengan spesialis penyakit dalam menanyakan opini tentang penyakit maag, penyebab penyakit maag dan menanyakan dampak stress pada penyakit maag. Wawancara dengan ahli psikolog menayakan apa penyebab stress, bagaimana cara mengatasi stress dan fakta tentang pengaruh stress pada penyakit maag. Selanjutnya kuisioner, dalam kuisioner terdapat pertanyaan mengenai persepsi masyarakat tentang penyakit maag, persepsi masyarakat mengenai penyakit maag, apa yang diketahui masyarakat timbulnya penyakit maag. Terakhir dengan website resmi tentang program CSR dari PT. Kalbe, berdirinya PT. Kalbe, dan program CSR yang sudah dijalani mengenai penyakit maag. 


\section{Target Audiens}

Secara demografis target audiens pada perancangan kampanye sosial ini berusia 1725 tahun, dengan jenis kelamin pria dan wanita, berpendidikan SMA sampai pengguruan tinggi, sasaran masyarakat kota-kota besar seperti Tangerang, Jakarta dan Bandung, dengan status ekonomi sosial menengah.

Letak geografis yang ditujukan adalah kota-kota besar seperti Jakarta, Tangerang, dan Bandung. Karena kota tersebut merupakan kota yang mempunyai generasi produktif yang banyak sehingga mempunyai tingkat stress yang berbeda-beda. Secara psikografis, Menurut Depkes RI (2009) umur tersebut merupakan kategori umur masa remaja akhir. Remaja Akhir. Bisa menjangkau dengan teman sebaya, Mendekati peran sosial, Mencakup kemandirian emosional dengan orang tua dan yang lainnya, Bisa menyeleksi dalam mempersiapkan karir, Intelektual dalam keterampilan, Memiliki rasa tanggung jawab secara sosial, bisa menerapkan etika sebagai berprilaku.

Costumer insight pada perancangan ini cenderung kepada masyarakat dengan genarasi aktif. Generasi aktif cenderung mempunyai gaya hidup kurang teratur sehingga menjadi salah satu penyebab seseorang rentan terkena penyakit maag. Berada diwilayah kota besar, masyarakat memiliki prilaku tekanan hidup yang berbeda sehingga beban hidup.

Costumer journey merupakan salah satu kegiatan yang dilakukan pada target sasaran dalam aktifitas sehari-hari. Pada tahap ini juga bisa menenntukan media yang ingin disampaikan pada kampanye sosial sehingga dapat mempermudah penyampaian pesan dalam kampanye sosial.

\section{Strategi Perancangan}

Strategi komunikasi yang dilakukan menggunakan pedekatan persuasif. Menurut Erwin P. Betinghaus (1973) dalam Candara S\& Naning S (2019, h. 83), komunikasi persuasif yaitu sebuah kegitan untuk mempengaruhi perbuatan seseorang antara pembicara dan pendengar dengan melalui perantara berbagai macam media. Kesimpulannya, Pendekatan komunikasi persuasif yaitu pendekatan untuk menyampaikan informasi kepada orang lain mengenai pentingnya perubahan sosial dalam kehidupannya. Dalam pendekatan komunikasi terdapt secara verbal dan visual, berikut penjelasannya:

1) Pendekatan verbal

Dalam perancangan ini pendekatan verbal yang digunakan bersifat informatif. Dalam pendekatan ini menggunkan Bahasa non formal dan santai. Penambahan teks pada video mempermudah agar masyarakat mudah mengerti apa yang ingin disampaikan. 


\section{2) Pendekatan visual}

Pada pendekatan visual menampilkan aktvitas keseharian agar mudah dipahami oleh khalayak. Visual yang ditampilkan merupakan beberapa aktifitas meluangkan waktu sejenak yang bisa yang mudah dilakukan oleh khalayak agar pesan mudah diterapkan.

\section{Tujuan dan Pendekatan Komunikasi}

Tujuan perancangan kampanye ini yaitu untuk membujuk masyarakat terhindar dari penyakit maag yang diakibatkan dari stress. Materi pesan yang yang ingin disampaikan yaitu bagaimana cara masyarakat untuk meluangkan waktu untuk istirahat sejenak agar terhindar dari stress untuk menekan asam lambung naik. Gaya bahasa digunakan yaitu metafora. Mengutip dari portal-ilmu.com majas metafora merupakan penggunaan objek dengan pesan yang ingin disampaikan bersifat sama melalui suatu ungkapan. Refrensi gaya visual yang digunakan

\section{Mandatory}

Mandatory yaitu menjelaskan lembaga/perusahaan yang bekerja sama dalam perancangan suatu strategi. Perusahaan yang bekerjasama dalam perancangan kampanye sosial ini adalah PT. Kalbe Farma Tbk, karena Kalbe merupakan salah satu produsen obat terbesar di Indonesia yang terpercaya dan perusahaan mempunyai program kampanye untuk mengatasi maag.

\section{Strategi Kreatif dan Media}

Strategi kreatif pada perancangan kampanye ini yaitu dengan iklan layanan masyarakat video untuk mempermudah khalayak menerapkan dan melihat visual dengan jelas agar mudah dilakukan.

Menurut Christopher Gilson \& Harold W (1980, h. 378) strategi kreatif dibagi menjadi 3. Yang pertama mempersiapkan informasi yang tepat agar mempermudah bentuk strategi yang sudah direncanakan terhadap komunikasi iklannya. Kedua, menempatkan posisi iklan dengan tujuan iklan yang dihasilkan sesuai dengan informasi yang sudah didapat. Ketiga, melakukan presentasi dengan persetujuan rancangan yang sudah dibuat dan diproduksi. Dalam perancangan video kampanye sosial meliputi copywriting, rencana visualisasi, storyline, storyboard. 


\section{Copywriting}

Copywriting yang digunakan terdiri dari tagline yaitu \#MenolakMaag, headline yaitu meluangkan waktu sejenak, subheadline yaitu cukup 15-20 menit saja dan body copy yaitu meluangkan diwaktu istirahat saat beraktivitas merupakan salah satu mengelola stress untuk menekan asam lambung naik.

\section{Rancangan Visual}

Pada pemilihan media yang digunakan yaitu kampanye sosial yaitu video iklan layanan masyarakat. Alasan mengambil iklan layanan masyarakat salah satu penyampaian pesan untuk mengajak dan mendidik dengan tujuan mendapatkan keuntungan sosial. keuntungan sosial meliputi pengetahuan kesadaran sikap dan perubahan prilaku.

\section{Storyline}

\begin{tabular}{|l|l|}
\hline Scene 1 & $\begin{array}{l}\text { Video } \\
\text { Seorang laki-laki sedang mengetik dan melihat jam lalu } \\
\text { bersandar dikursi dengan kedua tangan dibelakang kepala } \\
\text { sambil menghela nafas. } \\
\text { Audio } \\
\text { V.O : "Saat lelah bekerja, menyempatkan waktu istirahat } \\
\text { sejenak" }\end{array}$ \\
\hline Scene 2 & $\begin{array}{l}\text { Video } \\
\text { Seorang laki-laki yang mencari tempat duduk untuk tidur } \\
\text { diruang tunggu } \\
\text { Audio } \\
\text { V.O: "Lelah belajar, tidur sejenak" }\end{array}$ \\
\hline Scene 3 & $\begin{array}{l}\text { Video } \\
\text { Seorang laki-laki sedang mendengarkan musik di kamar } \\
\text { dengan expresif } \\
\text { Audio } \\
\text { V.O : "Mendengarkan alunan musik" }\end{array}$ \\
\hline
\end{tabular}




\begin{tabular}{|l|l|}
\hline Scene 4 & $\begin{array}{l}\text { Video } \\
\text { Mendegarkan music sambil berjalan } \\
\text { Audio } \\
\text { V.O: "Dan menikmati alunannya " }\end{array}$ \\
\hline Scene 5 & $\begin{array}{l}\text { Video } \\
\text { Dibawah pohon rindang } \\
\text { Audio } \\
\text { V.O : "Melihat pemandangan sejuknya pohon" }\end{array}$ \\
\hline Scene 6 & $\begin{array}{l}\text { Video } \\
\text { Dua orang yang sedang mengobrol } \\
\text { Audio } \\
\text { V.O : "Menyempatkan untuk mengobrol dengan teman" }\end{array}$ \\
\hline Ending & $\begin{array}{l}\text { Video } \\
\text { Sekumpumpulan remaja sedang bercanda } \\
\text { Audio } \\
\text { V.O : "Dan bercanda dengan teman-teman, semua karena itu } \\
\ldots \text { Dipersembahkan oleh : (logo kalbe dan dinkes) }\end{array}$ \\
\hline blackseen $]$
\end{tabular}




\section{Storyboard}

Storyboard yang merupakan sketsa ide yang disusun sesuai naskah yang terdapat di storyline.

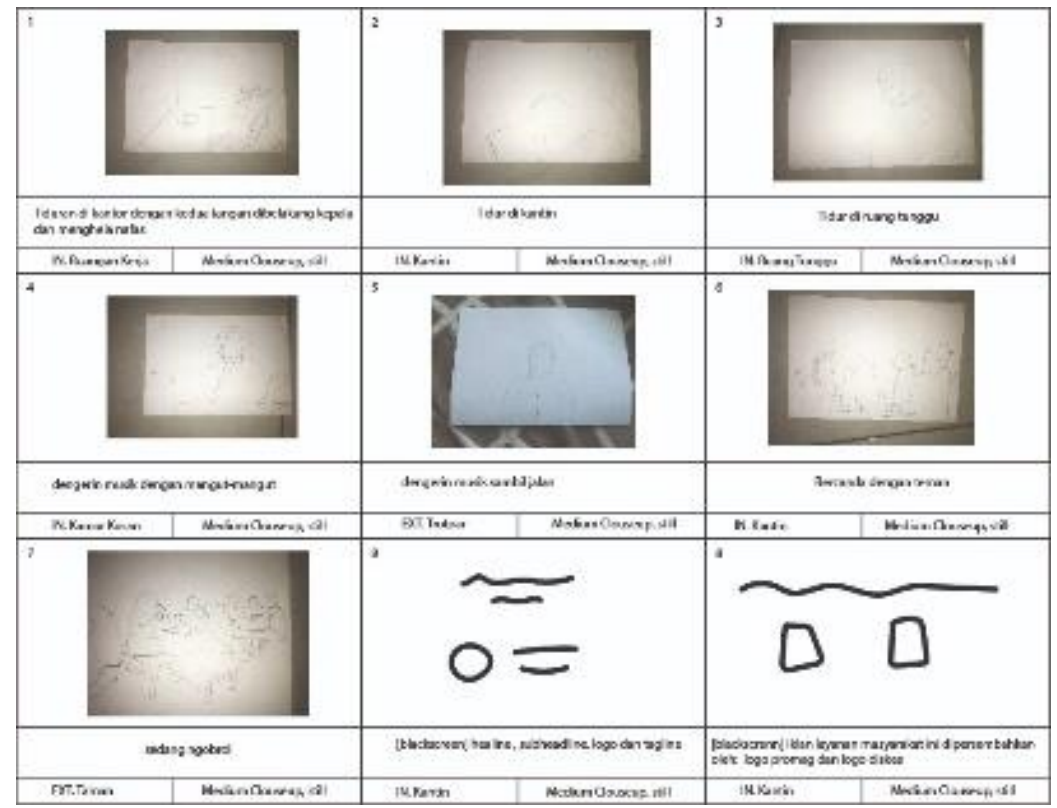

Gambar 1. Storyboard

Sumber: Pribadi (2020)

\section{HASIL DAN PEMBAHASAN}

\section{Format Desain}

Perancangan kampanye sosial menggunakan video dengan format (.mp4) dengan ukuran frame 1920x1080 px, frame $60 \mathrm{fps}$, aspek rasio 16:9 karena standart video dengan kualitas visual yang baik.

\section{Tata Letak}

Pada perancangan ini layout merupakan susunan unsur visual dengan menarik, mudah dimengerti, dan memberi kesan menarik. Pada layout perancangan kampanye melalui video ini yaitu menggunakan berbagai macam angle camera. Angle camera yang digunakan yaitu closeup, medium closeup, big clouseup, longshot. 


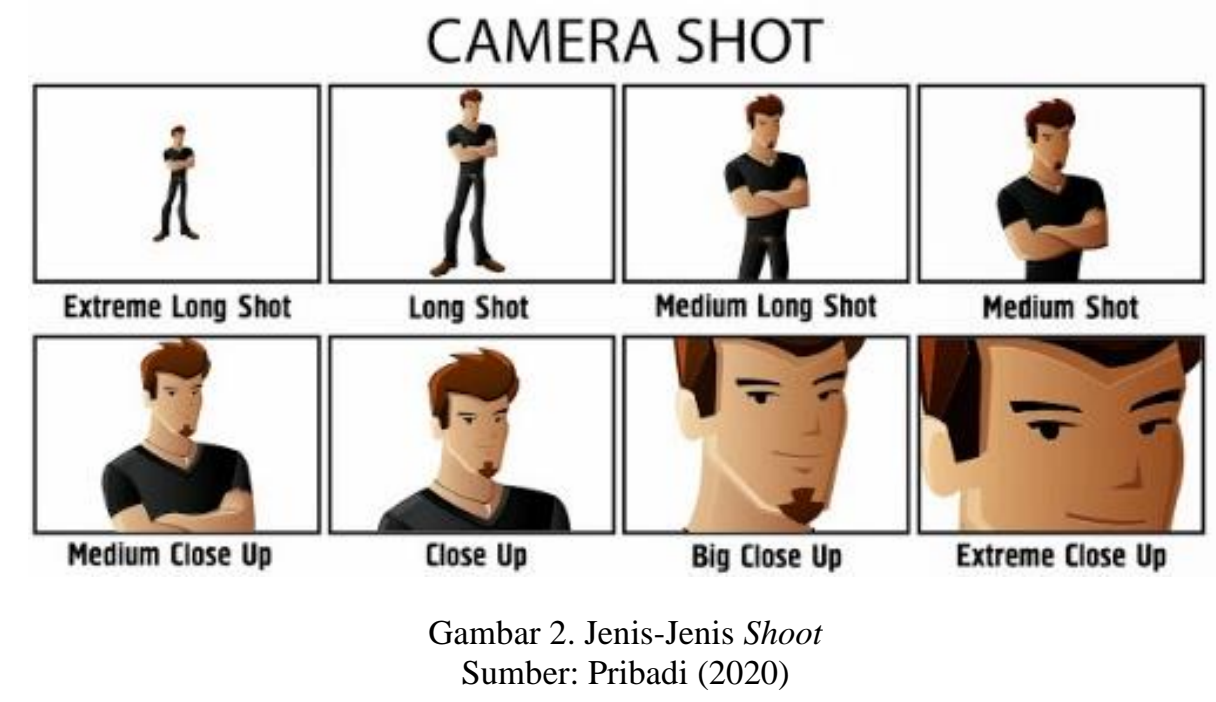

\section{Tipografi}

Dalam perancangan ini menggunakan huruf bison dan rockwell. Huruf yang digunakan yaitu penggunaan huruf dalam perancangan kampanye ini mengunakan font dengan kesan santai namun nyaman saat dibaca.

\section{ABCDEFGH IJKLMNOPQ RSTUVWXYZ 1234567890 \\ Gambar 3. Font Bison}

Sumber: https://www.dafontfree.io/bison-font-family/ (2020) 


\section{A B C D E F G H \\ I J K L M N O P Q \\ R S T U VW XY Z \\ abcdefghij \\ $\mathrm{klmnopqrstu}$ \\ $\mathrm{v}$ w x y z \\ 1234567890}

Gambar 4. Font Rockwell

Sumber: https://freefontsfamily.com/rockwell-font-free/ (2020)

\section{Ilustrasi}

Ilustrasi merupakan bentuk visual dengan harapan dari ketidakmungkinan yang bersifat maya yang tidak jauh dari bayangannya dalam berbagai diverikasi.

\section{KESIMPULAN}

Masih banyak masyarakat yang belum mengetahui penyebab penyakit maag dari stress maka dari itu perancangan membuat kampanye sosial. kampanye ini merupakan program Corporate Social Responsibilty (CSR) dengan PT. Kalbe. Video ini dirancang bagaimana cara meluangkan waktu sejenak untuk mengatasi stress dan menekan tingkat asam lambung naik. Perancangan video kampanye sosial ini penting untuk dikembangkan Kembali. Mengigat data yang didapatkan dari kuisioner dan wawancara masih kurang. Maka dari itu, perancangan selanjutnya disarankan untuk melakukan observasi dan wawancara secara langsung ke lebih banyak pihak yang berkaitan.

\section{DAFTAR PUSTAKA}

Candrasari, S., \& Naning, S. (2019). Strategi Komunikasi Persuasif Dinas Kesehatan Kabupaten Bogor Dalam Penyuluhan Penyakit Kaki Gajah. Kalbisocio (Jurnal Bisnis dan Komun, 6(1), 80-8.

Jannah M (2011). Perancangan Sistem Pakar Untuk Mendiagnosa Penyakit Lambung Dengan Metode Dempster Shafer. Universitas Sumatera. 
Kalbe (2020). Keberlanjutan Korporasi Kalbe. Keberkelanjutan. Dikutip dari https://www.kalbe.co.id/id/keberlanjutan (Diakses 11 Januari 2020)

Maniagasi, E. N. (2019) Hubungan Tingkat Stress Terhadap Gejala Gastritis Pada Pasien Di Rumah Sakit Umum Bhakti Rahayu Kota Surabaya. Undergraduate thesis, Universitas Merdeka Surabaya.

Merita, M., Sapitri, W. I., \& Sukandar, I. (2018). Hubungan tingkat stress dan pola konsumsi dengan kejadian gastritis di Puskesmas Pakuan Baru Jambi. Jurnal Akademika Baiturrahim Jambi, 5(1), 51-58.

Sukarmin (2012) . Keperawatan Pada Sistem Pencernaan, Jakarta: Pustaka Pelajar

Tarmawan, I. (2010). STRUKTUR DAN PROSES KOMUNIKASI DALAM IKLAN MINUMAN BIR "NOVA SCHIN\&quot;. Visualita Jurnal Online Desain Komunikasi Visual, 2(2). https://doi.org/10.33375/vslt.v2i2.1076 